\section{Cost of Life: Lessons from the Paddington Disaster} Dr. Anne Eyre

Centre for Disaster Management, Coventry University, UNITED KINGDOM

On 05 October, 1999, a commuter train going in to London crashed into an express train. In the first 24 hours, $>3,900$ calls were received by the Casualty Bureau with over 7,000 people reported as possibly having been on the two trains. Thirty-one people died and dozens were injured. This presentation will highlight some key issues arising from the management of the disaster including:

1) The emergency services' response: rescue and body recovery;

2) The impact of media speculation on the disaster response;

3) The role of family liaison officers and the coroner;

4) Trauma support for disaster workers; and

5) The work of the inquiry.

What Have We Learned?

The disaster and its aftermath coincided with some key legal and political developments that may have a bearing on future disaster planning and response. These include new guidelines for doctors on post-mortems and liaison with relatives as well as forthcoming legislation on corporate manslaughter. The presentation will draw on research interviews as well as documentary evidence including the inquiry transcripts. It will highlight the value of a multidisciplinary approach for understanding the range of issues arising from this incident and its implications for future disaster management.

Keywords: crash; emergency medical services; guidelines; planning; response; system; trains; trauma

Email: A.EYRE@cov.ac.uk
Mental Health Support to the Kosovar Refugees:

Lessons Learned - A Canadian Perspective

Raymond Lafond

Social Work Consultant, Emergency Services, CANADA

On 30 April 1999, the United Nations High Commissioner for Refugees (UNHCR) asked the Government of Canada to accept 5,000 Kosovar refugees forced out of their country by the war in Kosovo. This presentation will review some of the guidelines used to deliver a basic mental health program to assist Kosovars of all ages manage the many stress reactions experienced as a result of the war and their sudden relocation to a distant country. The psycho-social reactions and concerns that the Kosovars experienced and the activities initiated to respond to their needs also will be examined.

The unique challenges of providing counseling services to people from a different cultural background and religion, through the intermediary of interpreters, also will be discussed. A brief description of major social and cultural issues that surfaced will be included as well as lessons learned in providing mental health services to Kosovars. The presentation also will highlight some innovative initiatives taken by Family Support Workers in the management and delivery of mental health services to the Kosovars.

Keywords: Canada, culture, Kosovo, mental health, psycho-social, reactions, refugees, religion, $\mathrm{UNHCR}$ 